\title{
Morfofisiologia de porta-enxerto de goiabeira irrigado com águas salinizadas sob doses de nitrogênio
}

\author{
Evandro Manoel da Silva, Reginaldo Gomes Nobre, Leandro de Pádua Souza,
} Railene Hérica Carlos Rocha Araújo, Francisco Wesley Alves Pinheiro, Luana Lucas de Sá Almeida

\section{Resumo}

A irrigação com água salina reduz a crescimento e a produtividade das culturas, havendo necessidade de técnicas que possibilitem o uso deste recurso natural de forma viável na fruticultura. Neste sentido, objetivou-se com o trabalho avaliar o efeito da salinidade da água de irrigação associado a distintas doses de nitrogênio sob a morfofisiologia de porta-enxerto de goiabeira cv. Paluma. Foi utilizado blocos inteiramente casualizado, testando 5 condutividades elétricas da água de irrigação - CEa $(0,3 ; 1,1 ; 1,9 ; 2,7$ e 3,5 dS m-1) e 4 doses de adubação nitrogenada $(541,1 ; 773,0$; 1004,9 e 1236,8 $\mathrm{mg} \mathrm{dm}^{-3}$ ), em esquema fatorial 5 x 4, com 4 repetições. O aumento da CEa a partir de $0,3 \mathrm{dS} \mathrm{m}^{-1}$ afetou negativamente a morfofisiologia de porta-enxerto de goiabeira cv. Paluma, principalmente, na fase mais jovem. A dose de $\mathrm{N}$ de $541,1 \mathrm{mg} \mathrm{dm}^{-3}$ estimulou o crescimento da maioria das variáveis nos porta-enxerto de goiabeira nos períodos estudados. A adubação nitrogenada não reduziu o efeito do estresse salino sobre as variáveis avaliadas.

Palavras-chave: Psidium guajava L.; salinidade; manejo da adubação

\section{Morphophysiology of guava rootstock irrigated with salted water under nitrogen doses}

\begin{abstract}
The irrigation with saline water reduces crop growth and yield, resulting in the need of new techniques that enable the use of this natural resource in fruit growing. In this sense, the objective of this study was to evaluate the effect of saline irrigation water associated with different nitrogen doses on guava rootstock cv. Paluma morphophysiology. The experiment was carried out in a completely randomized blocks design, testing 5 electrical conductivity of irrigation water - ECW $(0.3,1.1,1.9,2.7$ and $3.5 \mathrm{dS} \mathrm{m}^{-1}$ ) and four nitrogen doses for fertilization (541.1; 773.0; 1004.9 and $1236.8 \mathrm{mg} \mathrm{dm}^{-3}$ ), in

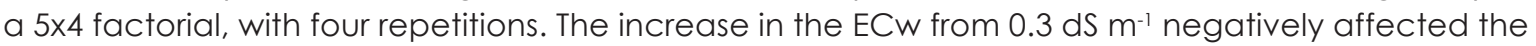
morphophysiology of guava rootstock cv. Paluma, especially during the younger phase of the crop. The $\mathrm{N}$ dose of $541 \mathrm{mg} \mathrm{dm}^{-3}$ stimulated the increase of most morphophysiological variables in guava rootstock during the period studied. The nitrogen fertilization did not reduced the salt stress effect on the evaluated variables.
\end{abstract}

Keywords: Psidium guajava L., salinity, fertilization management 


\section{Introdução}

A goiabeira (Psidium guajava L.) é uma planta rústica com capacidade de adaptação a diferentes condições edafoclimáticas. Com isso, sendo amplamente cultivada nas diversas áreas irrigadas do Brasil, situando-se entre as fruteiras de maior valor econômico, por seu fruto possuir grande aceitação nos mercados interno e externo (Cavalcante et al., 2005a; Freitas \& Alves, 2008).

A irregularidade na distribuição de chuvas associada às elevadas taxas de evapotranspiraçãotem limitado a disponibilidade de água de qualidade para irrigação em regiões áridas e semiárida, onde tem sido comum o uso de fontes de água com alta concentração de sais, limitando o crescimento e a produção das culturas (Neves et al., 2009), como no caso da goiabeira.

Cavalcante et al. (2010) verificaram em mudas de goiabeira cv. Paluma, que a salinidade da água de irrigação reduz o crescimento em altura, diâmetro do caule, número de folhas e a área foliar das plantas, sugerindo o estudo de técnicas que viabilizem o uso de água com problemas de sais na formação de mudas da espécie.

Em geral, a salinidade inibe o crescimento das plantas, em função dos efeitos tóxicos dos íons $\mathrm{Na}^{+}$e $\mathrm{Cl}^{-}$e à redução do potencial osmótico do solo (Munns, 2005). Estes íons provocam deficiência nutricional de $\mathrm{Ca}^{2+}, \mathrm{Mg}^{2+}, \mathrm{K}^{+}$e $\mathrm{NO}_{3}$ , causando alterações nas razões $\mathrm{K}^{+} / \mathrm{Na}^{+}, \mathrm{Ca}^{2+} /$ $\mathrm{Na}^{+}$e $\mathrm{NO}_{3}^{-} / \mathrm{Cl}^{-}$nos tecidos, o que compromete a homeostase iônica nas células, evidenciando a toxidade (Apse \& Blumwald, 2007).

Uma prática, que pode viabilizar o uso de água salina na irrigação, é o uso da adubação nitrogenada, embora sendo inexistentes trabalhos com a cultura da goiabeira. Conforme Blanco et al. (2008) a adubação nitrogenada reduz os efeitos prejudiciais em certa extensão de salinidade da água e do solo, por favorecer o aumento da absorção de $\mathrm{NO}_{3}^{-}$em relação

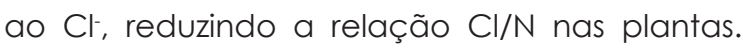
O nitrogênio desempenha função estrutural, fazendo parte de diversos compostos orgânicos vitais ao vegetal, como aminoácidos, proteínas, clorofila, entre outros (Alves et al., 2012).
Na literatura existem poucos trabalhos avaliando adubação nitrogenada na fase de produção de mudas da cultura da goiabeira. Franco et al. (2007) verificaram que o nitrogênio é o segundo nutriente mais exigido por mudas goiabeira, observando acúmulo de $552 \mathrm{mg}$ de N por planta na cv. Paluma em cultivo hidropônico. Dias et al. (2012) constaram que a dose média $773 \mathrm{mg}$ de $\mathrm{N} \mathrm{dm}^{-3}$ de substrato, propicia maiores valores de variáveis morfológicas de mudas de goiabeira do genótipo Paluma.

Diante o exposto, objetivou-se com o trabalho avaliar o efeito da salinidade da água de irrigação associado a doses de nitrogênio sob a morfofisiologia de porta-enxerto de goiabeira cv. Paluma.

\section{Material e métodos}

O experimento foiconduzido entre março e outubro de 2014, em casa de vegetação, no Centro de Ciências e Tecnologia Agroalimentar da Universidade Federal de Campina Grande, Pombal-PB, cujas coordenadas geográficas locais de referência são 648' 16" S; 3749' 15" O e altitude média de $144 \mathrm{~m}$.

Utilizou-se delineamento de blocos ao acaso, em esquema fatorial $5 \times 4$, cujos tratamentos resultaram de dois fatores: salinidade da água de irrigação em cinco condutividades elétricas (CEa): 0,3; 1,1; 1,9; 2,7 e 3,5 dS m-1 e quatro doses de nitrogênio: 541,$1 ; 773,0 ; 1004,9$ e $1236,8 \mathrm{mg} \mathrm{dm}^{-3}$ (70; 100; 130 e 160\% da dose de $\mathrm{N}$ recomendada para formação de mudas de goiabeira cv. Paluma em sacolas de polietileno de 1,2 L), com quatro repetições, sendo cada unidade experimental compostas por cinco plantas, onde foi avaliada duas plantas úteis da área central da parcela. $\square$

As CEa foram selecionados de acordo com citações de Távora et al. (2001) que classificaram a goiabeira na fase de crescimento inicial como sensível à salinidade, com a salinidade limiar no extrato de saturação do solo (CEes) e na água de irrigação (CEa) de 1,2 dS $\mathrm{m}^{-1}$ e $0,8 \mathrm{dS} \mathrm{m}^{-1}$, respectivamente. As doses de $\mathrm{N}$ foram determinadas com base na dose de $773 \mathrm{mg}$ de $\mathrm{N} \mathrm{dm}^{-3}$ recomendada por Dias et al. (2012) para mudas de goiabeira cv. Paluma propagados por estacas herbáceas, sendo este 
valor considerado $100 \%$ de $\mathrm{N}$.

As águas salinas foram preparadas pela adição de diferentes quantidades de sais de $\mathrm{NaCl}, \mathrm{CaCl}_{2} \cdot 2 \mathrm{H}_{2} \mathrm{O}$ e $\mathrm{MgCl}_{2} \cdot 6 \mathrm{H}_{2} \mathrm{O}$, na proporção de 7:2:1, relação esta predominante nas principais fontes de água disponíveis para irrigação no Nordeste Brasileiro (Medeiros, 1992), obedecendo-se a relação entre CEa e a concentração dos sais (mmolc $\left.L^{-1}=C E \times 10\right)$ (Rhoades et al. 1992).

Foram estudados porta-enxertos de goiabeira de cultivar Paluma, produzidos através de sementes germinadas em tubetes, semeandose quatro sementes por tubete na profundidade de $1,0 \mathrm{~cm}$. Utilizou-se tubetes plásticos com dimensões de $19 \mathrm{~cm}$ de altura e $6,3 \mathrm{~cm}$ de diâmetro, capacidade $288 \mathrm{~cm}^{-3}$, e abertura na parte inferior para permitir livre drenagem. Estes recipientes foram dispostos em bandejas com capacidade para 54 tubetes, apoiadas em bancadas metálicas (cantoneiras), a uma altura de $0,8 \mathrm{~m}$ do solo.

No preenchimento dos tubetes foi utilizado substrato composto de Neossolo flúvico + areia + esterco bovino curtido na proporção de $82 \% ; 15 \%$ e $3 \%$, respectivamente. Após o preparo deste substrato, uma amostra foi coletada, e suas características físicas e químicas (Tabela 1) analisadas no Laboratório de Solos e Plantas do Centro de Ciências e Tecnologia Agroalimentar da Universidade Federal de Campina Grande - CCTA/UFCG, conforme metodologia de Claessen (1997).

Tabela 1. Características físicas e químicas do substrato utilizado no experimento

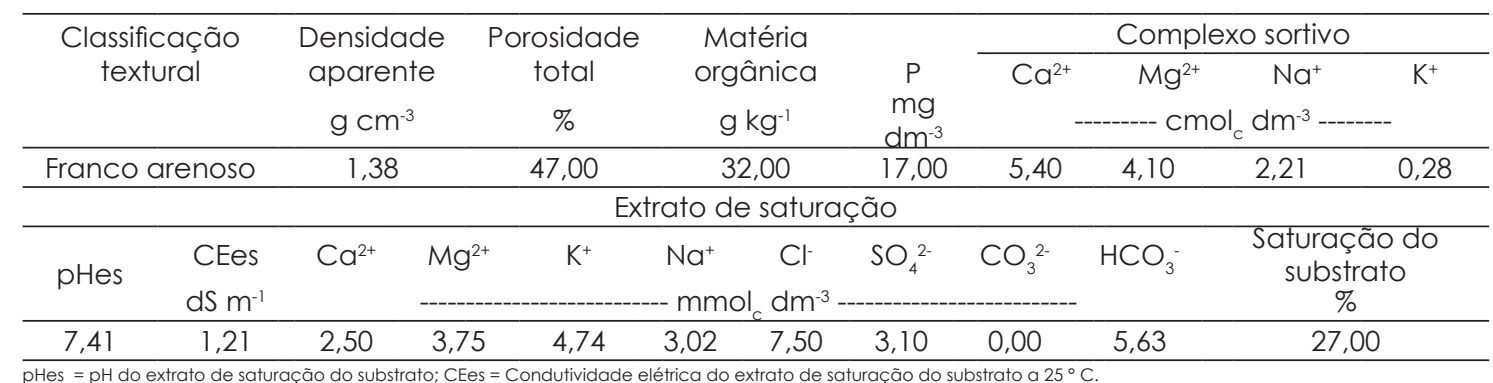

Após as plântulas apresentarem dois pares de folhas verdadeiras totalmente expandidas, realizou-se o desbaste, deixando-se apenas uma plântula por tubete, a de melhor vigor. Além disso, foram realizados outros tratos culturais, como capinas manuais e escarificação superficial do substrato para remoção de camadas compactadas.

A aplicação dos tratamentos láguas salinizadas e doses de N) que foi realizado após o desbaste, teve início aos 25 dias após a emergência de plântulas (DAE). As irrigações com águas salinas foram feitas, conforme - tratamento, com base na necessidade hídrica da planta, pelo processo de lisimetria de drenagem, sendo aplicado diariamente o volume retido no tubete, determinado pela diferença entre o volume aplicado e o volume drenado da irrigação anterior. As irrigações foram feitas duas vezes ao dia, sendo no início da manhã e final da tarde. Aplicou-se a cada 15 dias, uma fração de lixiviação de $15 \%$ com água de cada tratamento, baseado no volume aplicado nestes 15 dias, de modo a reduzir a salinidade do extrato de saturação do substrato.

A adubação nitrogenada foi dividida em 14 aplicações em partes iguais, realizadas a cada 10 dias. Utilizou-se como fonte de nitrogênio a ureia (45\% de N), com aplicações realizadas manualmente via fertirrigação com água de condutividade elétrica de $0,3 \mathrm{dS} \mathrm{m}^{-1}$ para todos os tratamentos. Usou-se esta água no intuito de evitar incrementos na CEa de cada tratamento pela salinidade do fertilizante diluído na água, o que poderia aumentar o estresse salino sobre as plantas.

Aos 130 e 190 DAE avaliou-se o crescimento dos porta-enxerto de goiabeira através da altura de plantas (AP), diâmetro de caule (DC), número de folhas (NF) e área foliar (AF), enquanto que nos períodos de 25 a $130 \mathrm{DAE}$ e de 130 a 190 DAE foram avaliados as variáveis fisiológicas referentes à taxa de crescimento absoluto (TCAap) e relativo da altura de planta 
(TCRap) e a taxa de crescimento absoluto (TCAdC) e relativo do diâmetro do caule (TCRdC).

A AP foi determinada medindo-se as plantas da superfície do solo até ponto de inserção do meristema apical. Avaliou-se o DC a uma altura de $4 \mathrm{~cm}$ do colo da planta. A determinação do NF foi feita por contagem de folhas que estavam com o limbo foliar totalmente aberto. A AF foi estimada pelo produto do comprimento e largura máxima do limbo, corrigido pelo coeficiente de 0,743, conforme Cavalcante et al. (2005b).

A TCAap e TCRap, e a TCAdc e TCRdc foram determinadas de acordo com metodologia descrita por Benincasa (2003).

As variáveis foram avaliadas mediante análise de variância, pelo teste $F(1$ e $5 \%$ de probabilidade) e, nos casos de efeito significativo, realizou-se análise de regressão polinomial linear e quadrática, utilizando-se do software estatístico SISVAR/UFLA. A escolha da regressão foi feita mediante melhor ajuste em base de coeficiente de determinação $\left(R^{2}\right)$ e levando-se em consideração uma provável explicação biológica.

\section{Resultados e discussão}

Verifica-se no resumo do teste $F$ (Tabela 2), efeito significativo dos níveis de salinidade da água de irrigação sobre a altura de planta (AP) aos $130 \mathrm{DAE}$, diâmetro do caule (DC), número de folhas (NF) e área foliar (AF) do porta-enxerto de goiabeira aos 130 e 190 DAE. Referente ao fator adubação nitrogenada observou-se efeito significativo sobre AP, DC, NF e AF aos 130 e 190 DAE. Outrossim, não se constatou interação significativa entre os fatores salinidade da água $x$ doses de nitrogênio ( $\mathrm{S} \times \mathrm{DN}$ ) sobre estas variáveis nas duas épocas de avaliação.

Tabela 2. Resumo da análise de variância para altura de plantas (AP), diâmetro de caule (DC), número de folhas (NF) e área foliar (AF) de porta-enxerto de goiabeira cv. Paluma irrigada com águas salinas e sob doses de adubação nitrogenada, aos 130 e 190 dias após a emergência - DAE

\begin{tabular}{|c|c|c|c|c|c|c|c|c|}
\hline \multirow{3}{*}{ Fonte de variação } & \multicolumn{8}{|c|}{ Teste F } \\
\hline & \multicolumn{2}{|c|}{ AP } & \multicolumn{2}{|c|}{$\mathrm{DC}$} & \multicolumn{2}{|c|}{ NF } & \multicolumn{2}{|c|}{$\mathrm{AF}$} \\
\hline & 130 & 190 & 130 & 190 & 130 & $190^{1}$ & 130 & $190^{1}$ \\
\hline Salinidades (S) & $6,39^{* *}$ & $1,42^{\text {ns }}$ & $7,76^{* *}$ & $7,91^{* *}$ & $18,97^{* *}$ & $5,36^{* *}$ & $5,59^{* *}$ & $3,69^{* *}$ \\
\hline Reg. linear & $20,35^{* *}$ & $2,72^{\text {ns }}$ & $22,04^{* *}$ & $19,47^{* *}$ & $73,91^{* *}$ & $15,86^{* *}$ & $18,80^{* *}$ & $9,24^{* *}$ \\
\hline Reg. quadrática & $1,12^{\text {ns }}$ & $2,77^{\text {ns }}$ & $2,15^{\text {ns }}$ & $10,34^{* *}$ & $0,79^{\text {ns }}$ & $0,80^{\text {ns }}$ & $0,29^{\text {ns }}$ & $4,24^{*}$ \\
\hline Doses de N (DN) & $14,08^{* *}$ & $17,82^{* *}$ & $20,22^{* *}$ & $33,52^{* *}$ & $7,77^{* *}$ & $14,02^{* *}$ & $17,44^{* *}$ & $9,55^{* *}$ \\
\hline Reg. linear & $32,30^{* *}$ & $48,37^{* *}$ & $54,64^{* *}$ & $95,43^{* *}$ & $22,45^{* *}$ & $33,19^{* *}$ & $49,07^{* *}$ & $25,96^{* *}$ \\
\hline Reg. quadrática & $9,62^{* *}$ & $4,88^{*}$ & $3,85^{\text {ns }}$ & $0,14^{\text {ns }}$ & $0,75^{\text {ns }}$ & $4,21^{*}$ & $3,19^{\text {ns }}$ & $2,57^{\mathrm{ns}}$ \\
\hline Interação S*DN & $0,61^{\mathrm{ns}}$ & $0,44^{\text {ns }}$ & $1,20^{\text {ns }}$ & $1,64^{\mathrm{ns}}$ & $0,70^{\text {ns }}$ & $1,03^{\text {ns }}$ & $1,23^{\text {ns }}$ & $0,60^{\text {ns }}$ \\
\hline BLOCO & $4,43^{* *}$ & $1,94^{\text {ns }}$ & $2,93^{*}$ & $3,97^{*}$ & $7,53^{* *}$ & $2,93^{*}$ & $6,54^{* *}$ & $2,25^{\text {ns }}$ \\
\hline CV (\%) & 9,52 & 13,51 & 5,91 & 6,50 & 16,53 & 12,46 & 19,37 & 16,73 \\
\hline
\end{tabular}

O incremento na salinidade da água de irrigação causou efeito linear decrescente de $3,97 \%(1,15 \mathrm{~cm})$ por aumento unitário na CEa sobre a AP aos 130 DAE (Figura 1A). As plantas irrigadas com água de CEa de 3,5 dS $\mathrm{m}^{-1}$ sofreram reduções na AP de 12,71\% (3,70 $\mathrm{cm}$ ) em relação as plantas irrigadas com água de menor CEa $\left(0,3 \mathrm{dS} \mathrm{m}^{-1}\right)$. A água salina da irrigação reduz o potencial osmótico do solo que, consequentemente, aumenta as forças de retenção, diminuindo a absorção de água pela planta e a turgescência das células, a qual afeta as taxas de elongação e divisão celular, provocando redução do crescimento (Ashraf \& Harris, 2004).
Os dados de AP aos 130 DAE ajustaramse ao modelo quadrático pelo incremento da dose de nitrogênio, havendo aumento até a dose de $680 \mathrm{mg} \mathrm{dm}^{-3}$, onde as plantas atingiram AP de $29,0 \mathrm{~cm}$ que, permaneceu constante até $719 \mathrm{mg} \mathrm{dm}^{-3}$, a partir de onde ocorreram reduções. Contudo, aos 190 DAE, o aumento na adubação nitrogenada afetou negativamente a AP (Figura 1B), causando redução linear de $8,24 \%(3,3 \mathrm{~cm})$ por aumento de cada $231,9 \mathrm{mg}$ $\mathrm{dm}^{-3}$, ou seja, $24,72 \%$, nas plantas adubadas com a dose de $1236,8 \mathrm{mg} \mathrm{dm}^{-3}$ em relação as a que receberam $541,1 \mathrm{mg} \mathrm{dm}^{-3}$.

Ressalta-se que aos 130 DAE as plantas estivessem em intensa divisão celular em relação 
aos 190 DAE, havendo maior exigência na dose de nitrogênio para obtenção de maior crescimento, pois, o nitrogênio atua na produção de novas células e tecidos (Taiz \& Zeiger, 2013).

Em relação aos 190 DAE, pode-se afirma que o decréscimo da AP pode estar associado a algum desequilíbrio nutricional causado pelo excesso do $\mathrm{N}$ nas plantas, ou mesmo, pela redução do $\mathrm{pH}$ do substrato, ocasionado por meio da liberação de $\mathrm{H}^{+}$produzidos durante o processo de nitrificação da ureia aplicada, conforme verificado por Silva et al. (2014) em mudas de jaqueira aos 110 dias após a semeadura.

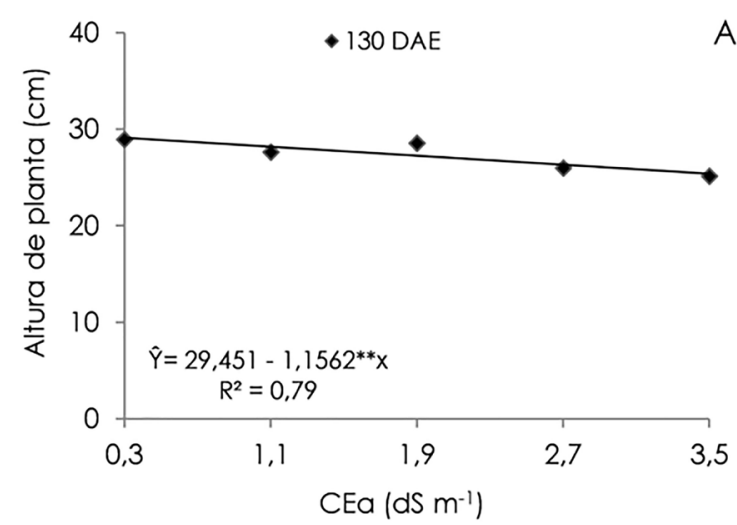

Verifica-se na Figura 2A, efeito linear decrescente no DC no período de 130 DAE pelo aumento gradual na salinidade da água de irrigação, com perda de 2,63\% por aumento unitário de CEa; enquanto que, aos 190 DAE o melhor ajuste dos dados foi em equação quadrática, com o DC atingindo maior valor de 3,31 mm no nível de CEa de 1,5 dS m-1 (Figura 2A). Verifica-se que na fase mais jovem (130 DAE) as plantas foram mais afetadas pela salinidade, enquanto que aos 190 DAE as plantas possam ter adquirido adaptação em consequência do maior tempo de exposição à água salina, resultando em aumento do diâmetro até este nível de salinidade.

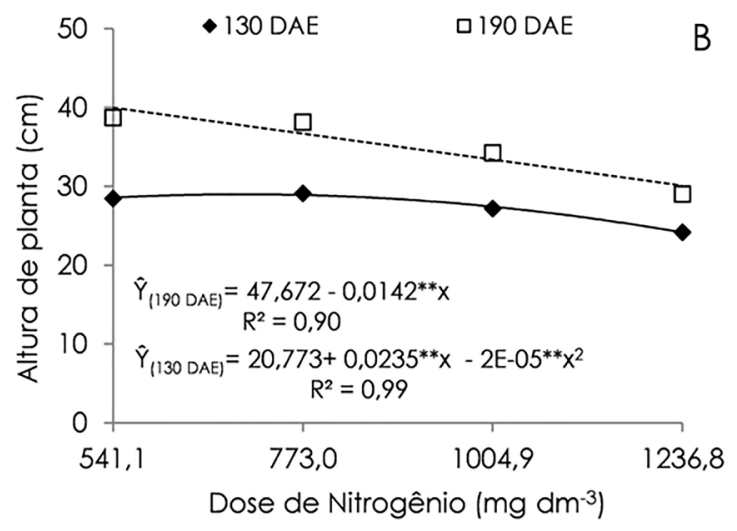

Figura 1. Altura de planta - AP de porta-enxerto de goiabeira em função da salinidade da água de irrigação - CEa aos 130 dias após a emergência - DAE (A) e doses de nitrogênio aos 130 e 190 DAE (B)
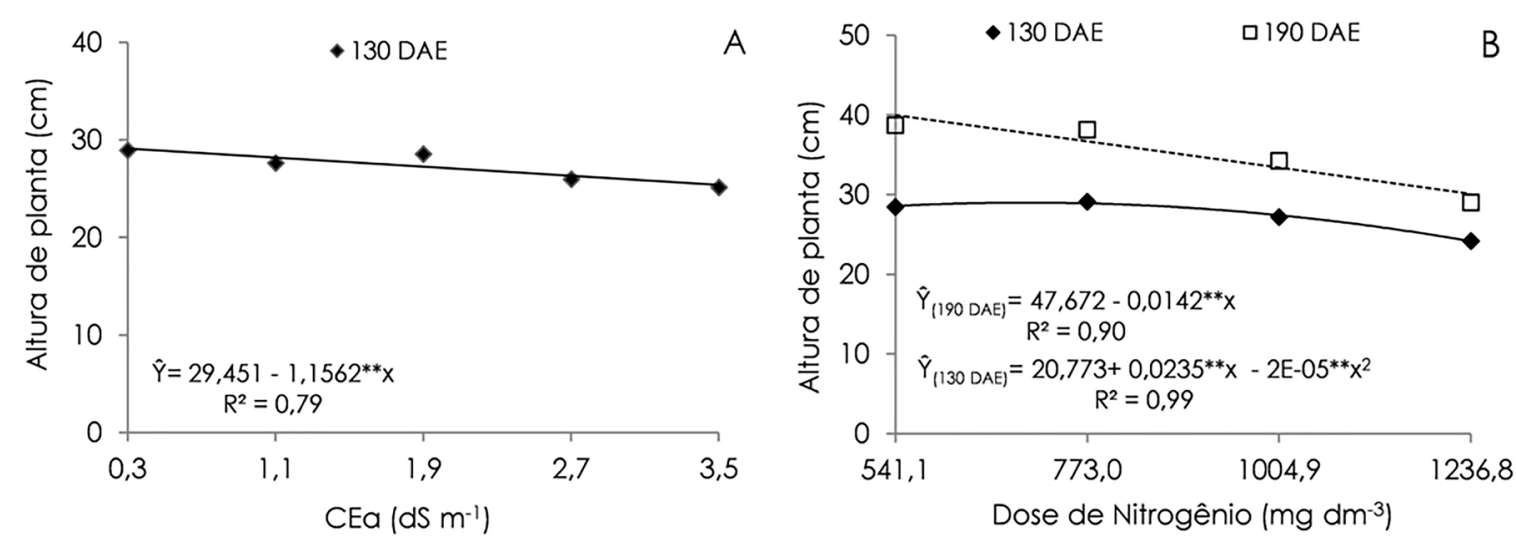

Figura 2. Diâmetro do caule - DC de porta-enxerto de goiabeira em função da salinidade da água de irrigação - CEa (A) e doses de nitrogênio (B) aos 130 e 190 dias após a emergência-DAE

O aumento gradual na dose $\mathrm{N}$ causou reduções sobre o DC aos 130 e 190 DAE, que segundo equações de regressão (Figura 2B) houve perdas lineares de 12,24\% (130 DAE) e 17,49\% (190 DAE), equivalente a 0,36 mm e 0,61 $\mathrm{mm}$ nas plantas que receberam a dose 1236,8 $\mathrm{mg} \mathrm{dm}^{-3}$ de $\mathrm{N}$ em relação a adubadas com
541,1 $\mathrm{mg} \mathrm{dm}^{-3}$. Embora esta variável tenha sido afetada negativamente em ambos os períodos de avaliação, constata-se que aos 190 DAE o efeito foi mais prejudicial, onde houve perdas de $1,75 \%$ a mais para cada aumento de $231,9 \mathrm{mg}$ $\mathrm{dm}^{-3}$ (Figura 2B). Sobretudo, a menor dose de $\mathrm{N}$, ou seja, de $541 \mathrm{mg} \mathrm{dm}^{-3}$ foi o suficiente para que 
os porta-enxerto de goiabeira atingissem o maior DC aos 130 e 190 DAE. Esta concentração de N está próximo do valor encontrada por Franco et al. (2007), correspondente a $552 \mathrm{mg}$ de $\mathrm{N}$ acumulado por planta em mudas de goiabeira 'Paluma' sob cultivo hidropônico aos 110 dias após o transplantio.

O NF foi afetado negativamente pelo incremento na salinidade da água de irrigação aos 130 e 190 DAE, promovendo reduções lineares de $11,46 \%$ e 8,02\% por aumento unitário de CEa, respectivamente (Figura 3A). Observa- se que as maiores reduções percentuais do NF ocorreram na fase mais jovem (130 DAE), podendo ser explicado pela maior sensibilidade das plantas de goiabeira à salinidade nesta fase, como confirmado por Távora et al. (2001). A redução do NF é uma forma de adaptação das plantas ao estresse salino, sendo este mecanismo adotado pela planta para reduzir as perdas de água pela transpiração e eliminar quantidades consideráveis de sais acumulado nas folhas (Willadino \& Câmara, 2010).
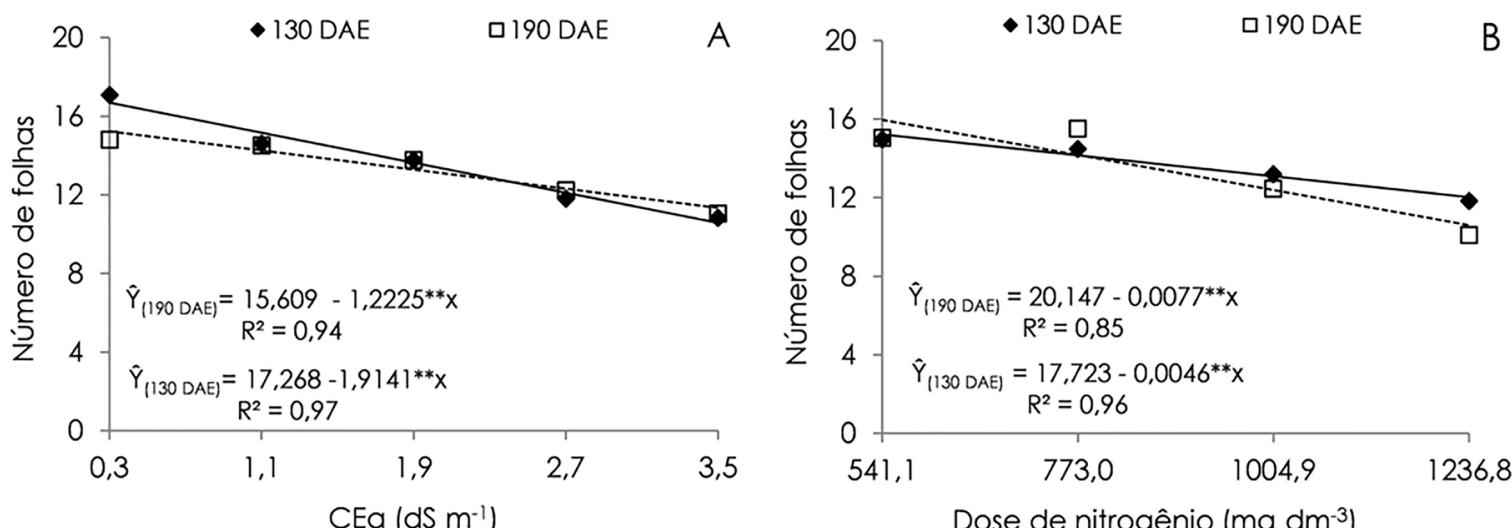

Figura 3. Número de folhas - NF de porta-enxerto de goiabeira em função da salinidade da água de irrigação - CEa (A) e doses de nitrogênio (B) aos 130 e 190 dias após a emergência - DAE

NF foi afetado negativamente pelo aumento das doses de nitrogênio, sofrendo reduções lineares de 6,95\% e 11,22\% sob o NF aos 130 e $190 \mathrm{DAE}$, respectivamente, para cada incremento de 231,9 $\mathrm{mg} \mathrm{dm}^{-3}$ (Figura 3B). Observase que as maiores reduções percentuais do NF pelo incremento nas doses de $\mathrm{N}$ ocorreram aos 190 DAE, chegando a atingir valores inferiores em relação aos 130 DAE após o uso da dose de $773 \mathrm{mg} \mathrm{dm}^{-3}$ (Figura 3B). Fenômeno que pode ter ocorrido pela intensificação do estresse salino causado pelo aumento na quantidade de ureia aplicada, principalmente aos 190 DAE, onde as plantas tiveram maior tempo de exposição ao estresse. Todavia, em ambas as épocas, as plantas produziram maior NF na menor dose nitrogênio, $541 \mathrm{mg}$ de $\mathrm{N} \mathrm{dm}^{-3}$.

Observa-se (Figura 4A), que os dados de AF aos 130 DAE ajustaram-se ao modelo linear com o aumento da salinidade na água de irrigação, onde ocorreu redução linear de 7,88\% na AF por aumento unitário de CEa; enquanto que aos $190 \mathrm{DAE}$, verificou-se comportamento quadrático, com a AF atingindo maior valor $\left(201,79 \mathrm{~cm}^{2}\right)$ no nível de 1,2 dS $\mathrm{m}^{-1}$. Pode-se afirmar que a AF das plantas de goiabeira aos 130 DAE são sensíveis ao aumento do estresse salino. Willadino \& Camara (2010) afirmam que em condições de salinidade, ocorre diminuição na expansão das folhas pela redução no processo de elongação das células, devido a diminuição na pressão de turgescência e na extensibilidade da parede celular, em consequência da menor absorção de água pela planta.

No período de 190 DAE pode ter ocorrido adaptação das plantas à salinidade na zona radicular, com as folhas adquirindo maior expansão, principalmente em comprimento, para compensar a área foliar perdida através da abscisão foliar. O limite de tolerância ou adaptação das plantas a um determinado nível de salinidade pode ocorrer pela compartimentalização dos íons $\mathrm{Na}^{+}$e $\mathrm{Cl}^{-}$ no vacúolo e, acúmulo de solutos orgânicos compatíveis no citoplasma, como prolina, glicinabetaína e alguns carboidratos, que 
reestabelecem o equilíbrio osmótico celular (Willadino \& Camara, 2010; Mendes et al., 2011).

O aumento das doses de $\mathrm{N}$ afetou negativamente a AF aos 130 e 190 DAE, onde foram registrados decréscimos lineares de $11,27 \%$ e $13,23 \%$ para cada aumento de 231,9 $\mathrm{mg} \mathrm{dm} \mathrm{dm}^{-3}$ (Figura 4B). A elevação nas doses de
$\mathrm{N}$ utilizando ureia como fertilizante pode elevar a salinidade no substrato, ou mesmo, aumentar rapidamente a concentração do íon amônio no solo, propiciando um efeito toxico à planta, com isso, provocando desordens fisiológicas, que compromete a divisão celular e reduz o crescimento da área foliar (Caproni et al., 2013).
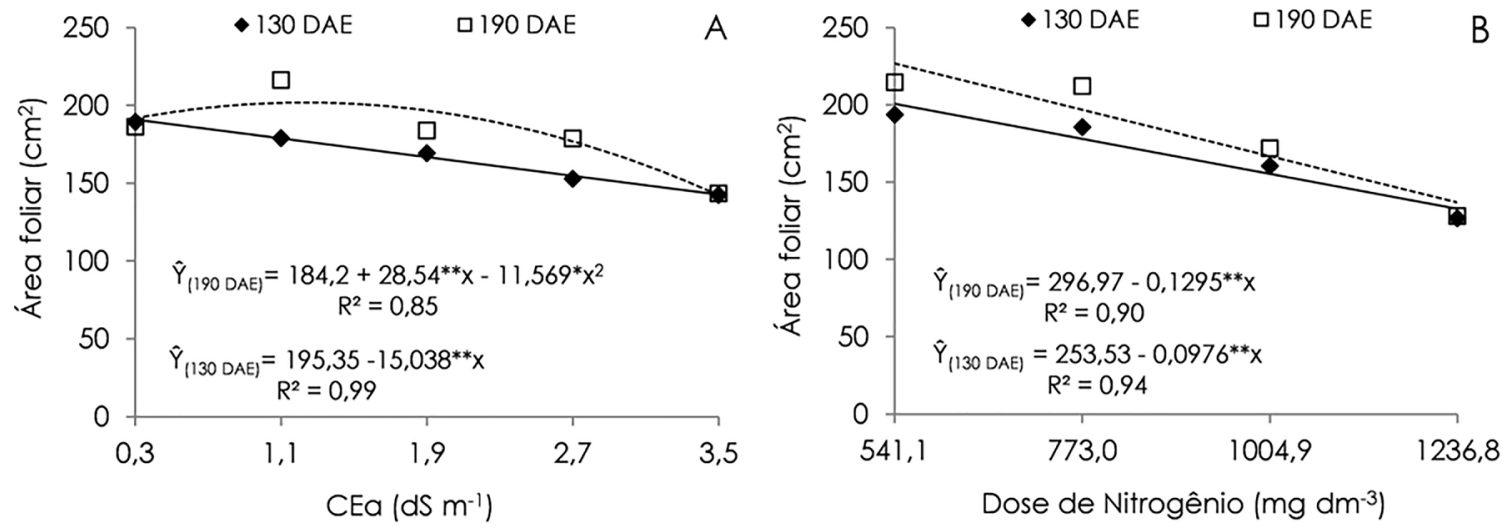

Figura 4. Área foliar - AF de porta-enxerto de goiabeira em função da salinidade da água de irrigação - CEa (A) e doses de nitrogênio (B) aos 130 e 190 dias após a emergência-DAE

Com base no teste $\mathrm{F}$ (Tabela 3 ) verificase que houve efeito significativo do fator salinidade da água de irrigação sobre a taxa de crescimento absoluto (TCAap) e relativo da altura de plantas (TCRap), taxa de crescimento absoluto (TCAdc) e relativo do diâmetro do caule (TCRdc) no intervalo de 25 a 130 DAE, enquanto que no período de 130 a 190 DAE não ocorreu efeito significativo da salinidade sobre estas variáveis. As doses de nitrogênio exerceu efeito significativo para todas estas variáveis em ambos os períodos de avaliação. No entanto, não se constatou interação significativa entre os fatores salinidade da água de irrigação $x$ doses de nitrogênio ( $S \times D N)$ sobre as variáveis analisadas nestas épocas.

Tabela 3. Resumo da análise de variância para taxa de crescimento absoluto (TCAap) e relativo da altura de planta (TCRap) e taxa de crescimento absoluto (TCAdc) e relativo do diâmetro do caule (TCRdc) de portaenxerto de goiabeira cv. Paluma irrigada com águas salinas e sob doses de adubação nitrogenada, aos 130 e 190 dias após a emergência - DAE

\begin{tabular}{|c|c|c|c|c|c|c|c|c|}
\hline \multirow{3}{*}{ Fonte de variação } & \multicolumn{8}{|c|}{ Teste $\mathrm{F}$} \\
\hline & \multicolumn{2}{|c|}{ TCAap } & \multicolumn{2}{|c|}{ TCRap } & \multicolumn{2}{|c|}{ TCAdC } & \multicolumn{2}{|c|}{ TCRdC } \\
\hline & $25-130$ & $130-190^{1}$ & $25-130$ & $130-190^{1}$ & $25-130$ & $130-190^{1}$ & $25-130$ & $130-190^{1}$ \\
\hline Salinidades (S) & $6,25^{* *}$ & $0,98^{\text {ns }}$ & $6,42^{* *}$ & $2,40^{\text {ns }}$ & $7,43^{* *}$ & $2,19^{\text {ns }}$ & $5,22^{*}$ & $2,01^{\text {ns }}$ \\
\hline Reg. Linear & $19,72^{* *}$ & $1,07^{\mathrm{ns}}$ & $21,02^{* *}$ & $4,38^{*}$ & $22,11^{* *}$ & $1,48^{\text {ns }}$ & $15,30^{* *}$ & $1,60^{\text {ns }}$ \\
\hline Reg. quadrática & $1,15^{\text {ns }}$ & $2,51^{\mathrm{ns}}$ & $1,67 \mathrm{~ns}$ & $4,21^{*}$ & $2,40 \mathrm{~ns}$ & $5,93^{*}$ & $1,75^{\text {ns }}$ & $5,53^{*}$ \\
\hline Doses de N (DN) & $14,40^{* *}$ & $6,44^{* *}$ & $13,18^{* *}$ & $5,06^{* *}$ & $18,22^{* *}$ & $7,72^{* *}$ & $15,46^{* *}$ & $3,97^{*}$ \\
\hline Reg. Linear & $33,62^{* *}$ & $18,78^{* *}$ & $30,72^{* *}$ & $14,97^{* *}$ & $48,73^{* *}$ & $19,74^{* *}$ & $39,29^{* *}$ & $9,70^{* *}$ \\
\hline Reg. quadrática & $9,03^{* *}$ & $0,15^{\text {ns }}$ & $8,08^{* *}$ & $0,11^{\text {ns }}$ & $3,57 \mathrm{~ns}$ & $1,418^{\text {ns }}$ & $4,90^{*}$ & $1,02^{\text {ns }}$ \\
\hline Interação (S*DN) & $0,68^{\text {ns }}$ & $0,71^{\text {ns }}$ & $0,87^{\text {ns }}$ & $0,73^{\text {ns }}$ & $1,24^{\mathrm{ns}}$ & $0,83^{\text {ns }}$ & $1,32^{\text {ns }}$ & $0,99^{\text {ns }}$ \\
\hline BLOCO & $4,41^{* *}$ & $0,84^{\text {ns }}$ & $4,01^{*}$ & $0,26^{\mathrm{ns}}$ & $3,24^{*}$ & $0,75^{\text {ns }}$ & $3,67^{*}$ & $0,51^{\mathrm{ns}}$ \\
\hline CV (\%) & 11,14 & 29,12 & 5,36 & 29,96 & 8,77 & 23,15 & 5,47 & 27,24 \\
\hline
\end{tabular}

a aumento da salinidade na água de irrigação exerceu efeito linear decrescente sobre a TCAap no intervalo de 25 a 130 DAE, com redução de 4,52\% por aumento unitário na CEa, (Figura 5A). A redução desta variável, em razão do estresse salino, pode estar relacionada ao desvio de substratos energéticos responsáveis pelo crescimento das plantas para a síntese de solutos orgânicos, de modo a realizar o ajustamento osmótico (Munns, 2005), ou mesmo, no efeito sobre a turgescência das células que afeta o crescimento e a divisão celular. 
Este resultado é condizente com Torres et al. (2014), onde verificaram em mudas de cajueiro, redução linear na TCAap de 4,4\% por aumento unitário na CEa de irrigação, avaliando os níveis de CEa entre 0,5 a 12,5 dS $\mathrm{m}^{-1}$ dos 10 aos 70 dias após a emergência.

De acordo com a equação de regressão (Figura 5B), verifica-se que a TCRap sofreu efeito quadrático com o incremento das doses de $\mathrm{N}$ no período de 25-130 DAE, cujo valor máximo $\left(0,2466 \mathrm{~cm} \mathrm{dia}^{-1}\right)$ foi obtido no intervalo das

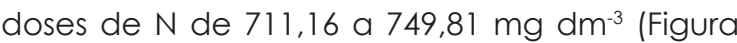
$5 B$ ), enquanto que durante o período de 130-190 DAE ocorreu decréscimo linear de $17,49 \%$ por aumento de 231,9 $\mathrm{mg} \mathrm{dm}^{-3}$ (Figura 5B). De modo geral, observa-se que as plantas na fase mais jovem (25-130 DAE) tiveram maior exigência de N. Este resultado assemelha-se com o observado por Dias et al. (2012) em que verificaram maior crescimento de mudas de goiabeira cv. Paluma na dose média de $773 \mathrm{mg}$ de $\mathrm{N} \mathrm{dm}^{-3}$.

Observa-se efeito negativo sobre a TCRap pelo aumento da CEa durante o período de 25-130 DAE, ocorrendo redução linear de $2,11 \%$ por aumento unitário de CEa (Figura 6A). Semelhante, Torres et al. (2014) verificaram decréscimo linear de 3,9\% sobre a TCRap de mudas de cajueiro anão precoce pelo aumento da CEa de 0,5 a 12,5 dS $\mathrm{m}^{-1}$, no período de 10 a 70 dias após a emergência. De acordo com Sousa et al. (2011), estes decréscimos estão relacionados à redução na disponibilidade de água ou o acúmulo excessivo de $\mathrm{Na}^{+}$e $\mathrm{Cl}^{-}$nos tecidos vegetais, os quais afetam os processos fisiológicos imprescindíveis às plantas.
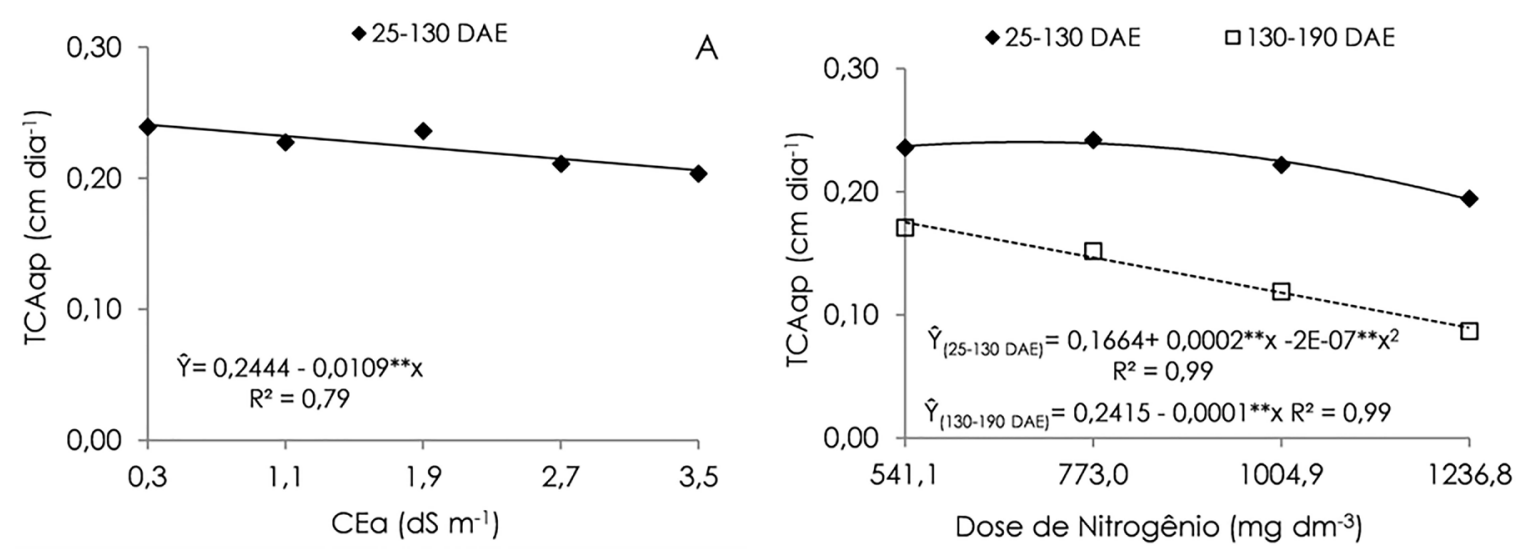

Figura 5. Taxa de crescimento absoluto da altura de planta - TCAap de porta-enxerto de goiabeira em função da condutividade elétrica da água de irrigação - CEa no período de 25 a 130 dias após a emergência - DAE (A) e doses de nitrogênio de 25 a 130 e de 130 a 190 DAE (B).
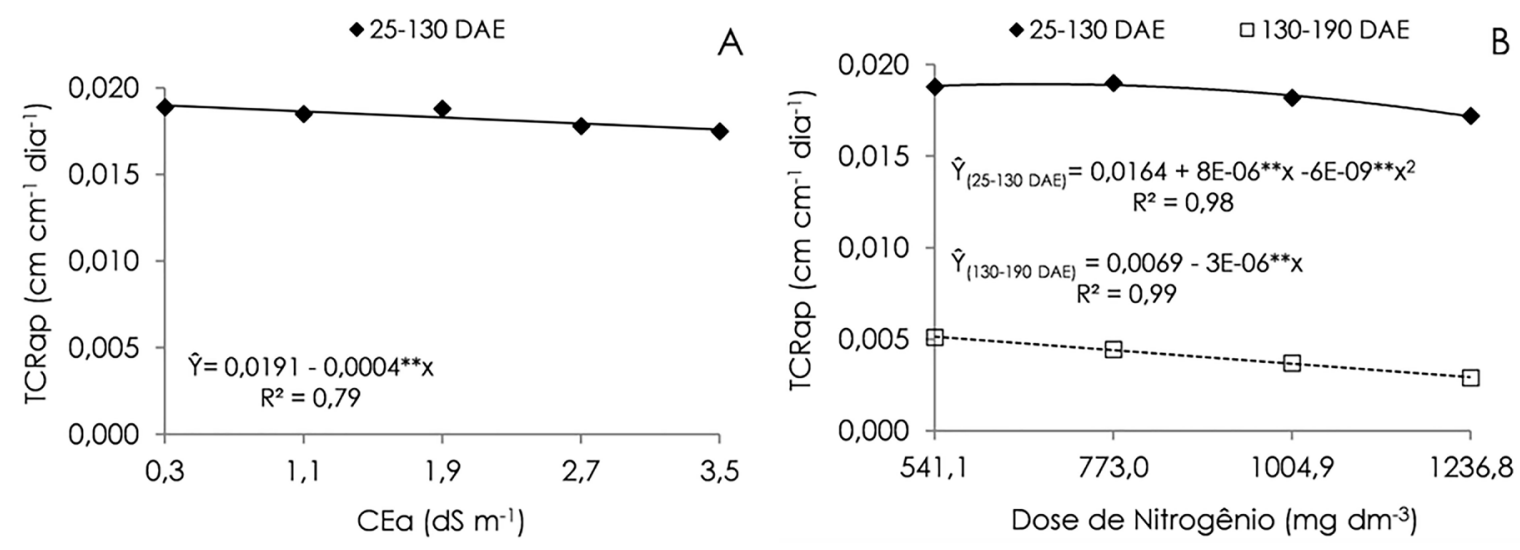

Figura 6. Taxa de crescimento relativo da altura de planta - TCRap de porta-enxerto de goiabeira em função da condutividade elétrica da água de irrigação - CEa (A) e doses de nitrogênio (B) durante os períodos de 25 a 130 e 130 a 190 dias após a emergência - DAE 
Conforme equação de regressão (Figura 6B) vê-se efeito quadrático na TCRap no período de 25-130 DAE pelo aumento na adubação nitrogenada, havendo acréscimo até a dose de $773 \mathrm{mg}$ de $\mathrm{N} \mathrm{dm}^{-3}$, que atingiu valor máximo de $0,0194 \mathrm{~cm} \mathrm{~cm}^{-1} \mathrm{dia}^{-1}$. No período de $130-$ 190 DAE o incremento na dose de $\mathrm{N}$ afetou negativamente a TCRap, ocorrendo efeito linear decrescente com redução de $10,91 \%$ por aumento de $231,9 \mathrm{mg} \mathrm{dm}^{-3}$. Esta resposta pode estar relacionada à maior exigência de $\mathrm{N}$ pelos porta-enxerto de goiabeira no período de 25-130 DAE para atingir maior crescimento em altura, enquanto que na fase de 130-190 DAE, é possível que o caráter salino da ureia juntamente com a salinidade da água de irrigação, tenham afetado negativamente a TCRap pelo aumento da adubação nitrogenada.

Pode-se observar na Figura 7A, que o aumento da salinidade na água de irrigação afetou negativamente a TCAdc durante $O$ período de 25 a $130 \mathrm{DAE}$, havendo decréscimo linear de $3,61 \%$ por aumento unitário na CEa. Torres et al. (2014) observaram que o aumento da CEa de 0,5 a 12,5 dS $\mathrm{m}^{-1}$ promoveu decréscimo linear sobre a TCAdc de mudas de cajueiro-anão na proporção de 6,0\% por aumento unitário na CEa, aos 70 dias após a emergência.
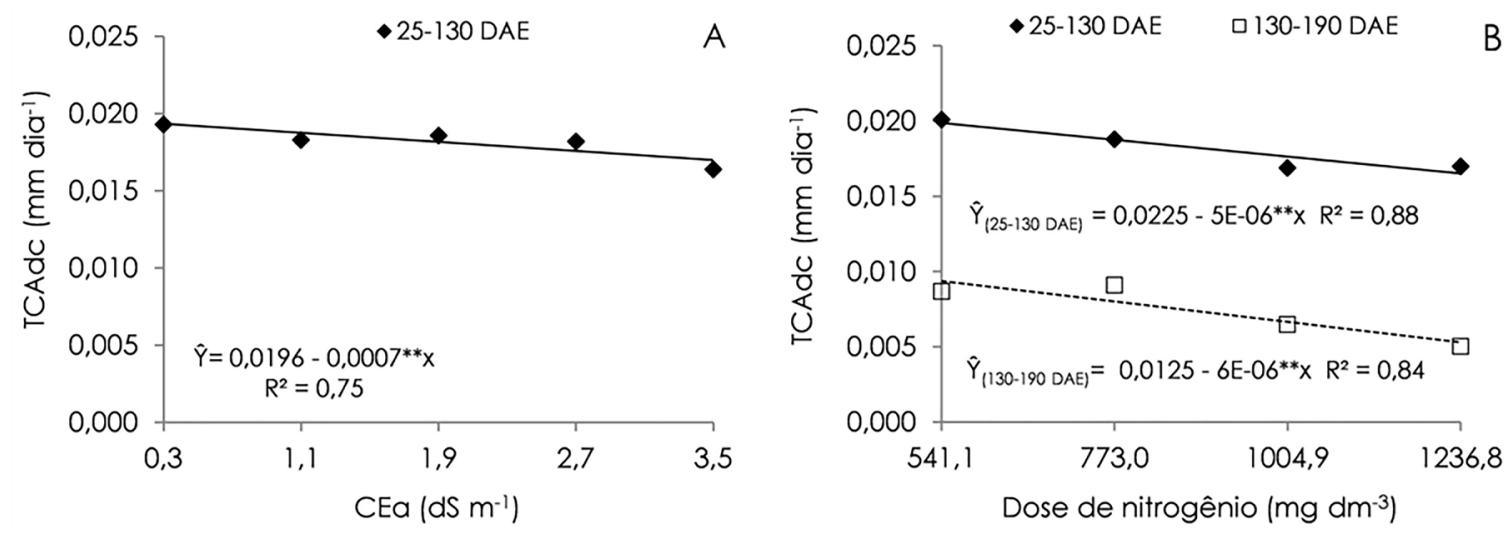

Figura 7. Taxa de crescimento absoluto do diâmetro do caule - TCAdc de porta-enxerto de goiabeira em função da condutividade elétrica da água de irrigação - CEa durante o período de 25 à 130 dias após a emergência - DAE (A) e doses de nitrogênio no período de 25 a 130 e 130 a 190 DAE (B)

O aumento na dose de $\mathrm{N}$ afetou negativamente a TCAdc durante os períodos de 25 a 130 e 130 a 190 DAE (Figura 7B), onde constata-se decréscimo linear de 18,3\% e 50,0\% nas plantas adubadas com $\mathrm{N}$ na dose de 1236,8 $\mathrm{mg} \mathrm{dm}^{-3}$ em relação às submetidas à dose 541,1 $\mathrm{mg} \mathrm{dm}^{-3}$, nos respectivos períodos de avaliação. Verifica-se que o efeito mais negativo sobre o crescimento do diâmetro dos porta-enxertos em função do aumento na dose de $\mathrm{N}$ ocorreu durante o período final de avaliação (130-190 DAE), havendo uma diferença de $33,4 \%$ em relação ao período de 25-130 DAE, quando se utilizou a maior dose (1236,8 $\left.\mathrm{mg} \mathrm{dm}^{-3}\right)$; sobretudo, nos dois períodos de avaliação a dose de $\mathrm{N}$ de $541 \mathrm{mg} \mathrm{dm}^{-3}$ promoveu maior crescimento no diâmetro dos porta-enxerto de goiabeira cv. Paluma.

O aumento da salinidade na água de irrigação exerceu efeito negativo sobre a
TCRdc no período de 25 a 130 DAE (Figura 8A), ocorrendo redução linear de 1,75\% por aumento unitário na CEa. Torres et al. (2014) observaram que o aumento na salinidade da água de irrigação de 0,5 a 12,5 dS $\mathrm{m}^{-1}$ promoveu efeito linear decrescente de 6,5\% por aumento unitário de CEa sobre TCRdc de mudas de cajueiro anão no período de 10 a 70 dias após a emergência.

Conforme as equações de regressão (Figura 8B) observa-se que o incremento nas doses de nitrogênio nos períodos de 25 a 130 e de 130 a 190 DAE promoveu reduções lineares na TCRdc pelo aumento na dose de N, equivalente a perdas de $7,69 \%$ e $30 \%$ nas plantas adubadas com a dose de 1236,8 $\mathrm{mg} \mathrm{dm}^{-3} \mathrm{em}$ relação às com $541,1 \mathrm{mg} \mathrm{dm}^{-3}$ nos respectivos períodos. Constata-se que assim como ocorrido para a TCAdc (Figura 7B), o efeito negativo do aumento das doses de $\mathrm{N}$ sobre a TCRdc ocorreu no período final de avaliação (130 a 190 DAE), 
havendo uma diferença de $22,3 \%$ em relação ao período de 25 a 130 DAE, quando se utilizou a maior dose de $\mathrm{N}\left(1236,8 \mathrm{mg} \mathrm{dm}^{-3}\right)$; embora sendo a menor dose $\left(541 \mathrm{mg} \mathrm{dm}^{-3}\right)$ que propiciou maiores ganhos de crescimento no diâmetro em ambos períodos de avaliação (Figura 8B).
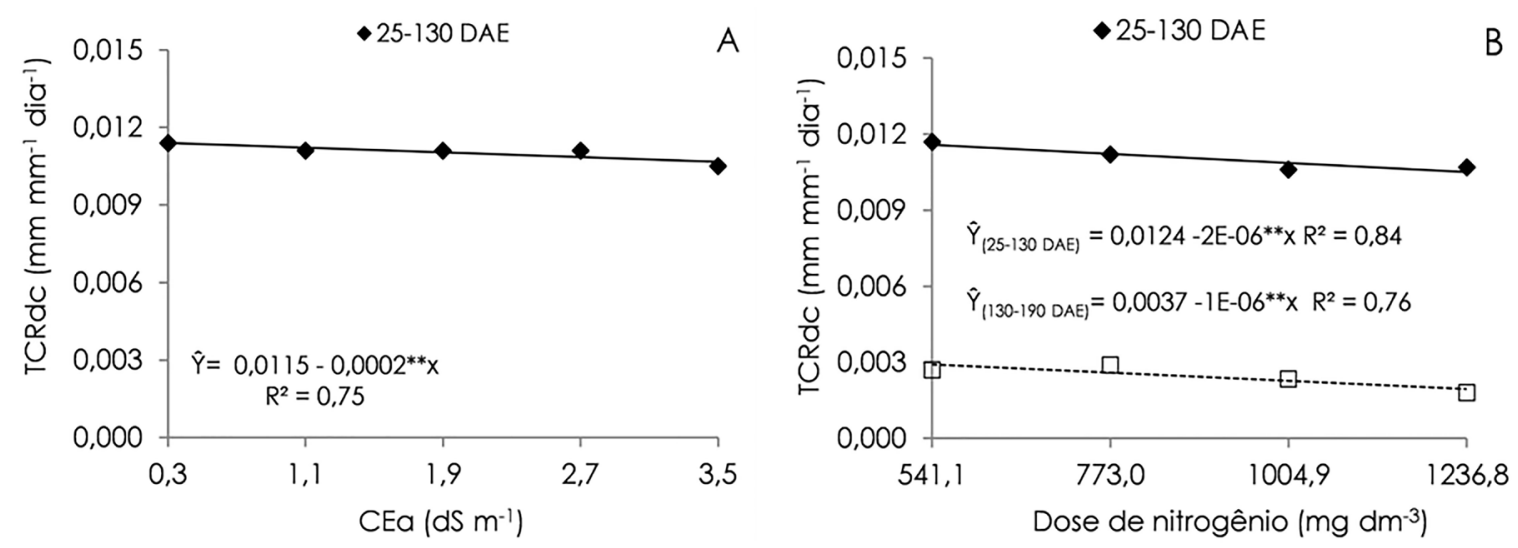

Figura 8. Taxa de crescimento relativo do diâmetro do caule - TCRdc de porta-enxerto de goiabeira em função da condutividade elétrica da água de irrigação - CEa durante o período de 25 a 130 dias após a emergência - DAE (A) e doses de nitrogênio no período de 25 a 130 e 130 e 190 DAE (B)

\section{Conclusões}

O aumento na salinidade da água de irrigação a partir de 0,3 dS $\mathrm{m}^{-1}$ afeta negativamente a morfofisiologia de portaenxerto de goiabeira cultivar Paluma, principalmente, na fase mais jovem.

A dose de $\mathrm{N}$ de $541,1 \mathrm{mg} \mathrm{dm}^{-3}$ estimula - crescimento da maioria das variáveis morfofisiológicas dos porta-enxerto de goiabeira nos períodos estudados.

A adubação nitrogenada não reduz o efeito do estresse salino sobre as variáveis avaliadas.

\section{Agradecimentos}

Ao Conselho Nacional de Desenvolvimento Científico e Tecnológico CNPq (Edital Universal 2013), pelo apoio financeiro para realização da pesquisa; e à Universidade Federal de Campina Grande - UFCG, Campus de Pombal-PB, pela disponibilidade da estrutura utilizada.

\section{Referências bibliográficas}

Alves, A.N., Gheyi, H.R., Uyeda, C.A., Soares, F.A.L., Nobre, R.G., Cardoso, J.A.F. 2012. Uso de águas salinas e adubação nitrogenada no cultivo da mamoneira BRS-energia. Revista Brasileira de Agricultura Irrigada 6: 151-163.

Apse, M.P., Blumwald, E. 2007. Na+ transport in plants. FEBS Letters 581: 2247-2254.

Ashraf, M., Harris, P.J.C. 2004. Potential biochemical indicators of salinity tolerance in plants. Plant Science, 166: 3-16.

Benincasa, M.M.P. 2003. Análise de crescimento de plantas, noções básicas. 2 ed. FUNEP, Jaboticabal, Brasil. 41 p.

Blanco, F.F., Folegatti, M.V., Henriques Neto, D. 2008. Doses de $\mathrm{N}$ e K no tomateiro sob estresse salino: I. Concentração de nutrientes no solo e na planta. Revista Brasileira de Engenharia Agrícola e Ambiental 12: p.26-33.

Caproni, C.M., Ramos, D. J., Vieira Neto, J., Silva, L.F.O., Simões, J.C., Pereira, W.R. 2013. Substratos e adubação nitrogenada na produção de mudas de maracujazeiro amarelo. Scientia Agraria 14: 69-75.

Cavalcante, L.F., Cavalcante, Í.H.L., Pereira, K.S.N., Oliveira, F.A., Gondim, S.C., Araújo, F.A.R. 2005b. Germination and initial growth of guava plants irrigated with saline water. Revista Brasileira de Engenharia Agrícola e Ambiental 9: 515-519.

Cavalcante, L.F., Vieira, M.S., Santos, A.F., Oliveira, W.M., Nascimento, J.A.M. 2010. Água salina e esterco bovino líquido na formação de mudas de goiabeira cultivar Paluma. Revista Brasileira de Fruticultura 32: 251-261.

Cavalcante, I.H.L., Cavalcante, L.F., Oliveira, F.A., Araújo, F.A.R. 2005a. Produção, exportação de nutrientes e composição mineral em dois genótipos de goiabeira. Científica 33: $112-119$.

Claessen, M. E. C. 1997. Manual de métodos de análise de solo. 2.ed. rev. atual. Embrapa-CNPS, Rio de Janeiro, Brasil. 212p.

Dias, M.J.T., Souza, H.A., Natale, W., Modesto, V.C., Rozane, D.E. 2012. Adubação com nitrogênio e potássio em mudas de goiabeira 
em viveiro comercial. Ciências Agrárias 33: 28372848 .

Franco, F.C., Prado, R.M., Brachirolli, L.F., Rozane, D.E. 2007. Curva de crescimento e marcha de absorção de macronutrientes em mudas de goiabeira. Revista Brasileira de Ciência do Solo 31: 1429-1437.

Freitas, B.M., Alves, J.E. 2008. Efeito do número de visitas florais da abelha melífera (Apis mellifera L.) na polinização da goiabeira (Psidium guajava L.) cv. Paluma, Revista Ciência Agronômica 39: 148-54.

Medeiros, J.F. Qualidade da água de irrigação e evolução da salinidade nas propriedades assistidas pelo "GAT" nos Estado do RN, PB e CE. 1992. 173 f. (Dissertação de Mestrado) Universidade Federal da Paraíba, Campina Grande, Brasil.

Mendes, B.S.S., Willadino, L., Cunha, P.C.R., Oliveira Filho, R.A., Camara, T.R. 2011. Mecanismo fisiológicos e bioquímicos do abacaxi ornamental sob estresse salino. Revista Caatinga 24: p.71-77.

Munns, R. Genes and salt tolerance: bringing them together. 2005. New Phytologist 167: 645663 ,

Neves, A.L.R., Lacerda, C.F., Guimarães, F.V.A., Hernandez, F.F.F., Silva, F.B., Prisco, J.T., Gheyi, H.R. 2009. Acumulação de biomassa e extração de nutrientes por plantas de feijão-de-corda irrigadas com água salina em diferentes estádios de desenvolvimento. Ciência Rural 39: 758-765.

Rhoades, J.P., Kandiah, A., Mashali, A.M. 1992. The use saline waters for crop production (Org). FAO, Roma, Itália. 133 p.

Silva, C.P., Garcia, K.G.V., Tosta, M.S., Cunha, C.S.M., Nascimento, C.D.V. 2014. Adubação nitrogenada no crescimento inicial de mudas de jaqueira. Enciclopédia Biosfera, 10: 174-180.

Sousa, A.B.O., Bezerra, M.A., Farias, F.C. 2011. Desenvolvimento inicial do clone BRS 275 de cajueiro sob irrigação com diferentes níveis salinos. Revista Brasileira de Agricultura Irrigada 4:166-171.

Taiz, L.; Zeiger, E. 2013. Fisiologia vegetal. 5. ed. Artmed, Porto Alegre, Brasil, 954p.

Távora, F.J.A.F., Ferreira, R.G., Hernandez, F.F.F. 2001. Crescimento e relações hídricas em plantas de goiabeira submetidas a estresse salino com Nacl. Revista Brasileira de Fruticultura 23: 441-446.

Torres, E.C.M., Freire, J.L.O., Oliveira, J.L., Bandeira, L.B., Melo, D.A., Silva, A.L. 2014. Biometria de mudas de cajueiro anão irrigadas com águas salinas e uso de atenuadores do estresse salino.
Nativa 2:71-78.

Willadino, L., Camara, T.R. 2010. Tolerância das plantas à salinidade: Aspectos fisiológicos e bioquímicos. Enciclopédia biosfera 6:1-23. 